\title{
Microwave and Ultrasound Augmented Leaching of Complicated Zinc Oxide Ores in Ammonia and Ammonium Citrate Solutions
}

\author{
Libo Zhang 1,2, Haoyu Li ${ }^{1,2}$, Jinhui Peng ${ }^{1,2}$, Chandrasekar Srinivasakannan ${ }^{3}$, Shiwei Li ${ }^{1,2, *}$ \\ and Shaohua Yin ${ }^{1,2}$ \\ 1 State Key Laboratory of Complex Nonferrous Metal Resources Clean Utilization, \\ Kunming University of Science and Technology, Kunming 650093, China; libozhang77@163.com (L.Z.); \\ 18213836872@163.com (H.L.); jhpeng@kmust.edu.cn (J.P.); wind2663543@126.com (S.Y.) \\ 2 Faculty of Metallurgical and Energy Engineering, Kunming University of Science and Technology, \\ Kunming 650093, China \\ 3 Chemical Engineering Program, The Petroleum Institute, P.O. Box 2533, Abu Dhabi 999041, UAE; \\ csrinivasakannan@pi.ac.ae \\ * Correspondence: lswei11@163.com; Tel.: +86-159-0880-5840; Fax: +86-871-6513-8997
}

Received: 9 May 2017; Accepted: 6 June 2017; Published: 12 June 2017

\begin{abstract}
Recovery of zinc from low grade zinc oxide ore is attempted with ammonia and ammonium citrate solutions augmented by microwave roasting and ultrasound radiation. The influence of the ammonia-ammonium ratio, roasting temperature, ultrasound power, and leaching time were assessed on the recovery of zinc. A maximum zinc recovery of $88.57 \%$ could be achieved at a roasting temperature of $673 \mathrm{~K}$, leaching temperature of $298 \mathrm{~K}$, stirring speed of $300 \mathrm{rpm}$, total ammonia concentration of $5 \mathrm{~mol} / \mathrm{L}$ with an ammonium citrate concentration of $1.2 \mathrm{~mol} / \mathrm{L}$, liquid to solid ratio of 5:1, the ultrasound power was $600 \mathrm{~W}$ and the leaching time was $120 \mathrm{~min}$. The enhancement in recovery with increases in the roasting temperature up to $673 \mathrm{~K}$ was attributed to the conversion of $\mathrm{ZnCO}_{3}$ to $\mathrm{ZnO}$. The phases of mineral samples and the reaction residues were characterized by $X$-ray diffraction (XRD).
\end{abstract}

Keywords: roasting; complicated zinc ores; mineral phase transformation; ammonia leaching

\section{Introduction}

With the availability of zinc sulfide ores dwindling, the need to identify alternative ores is imperative [1,2]. Zinc oxide ores are recently being considered as an appropriate alternative. However, the zinc oxide ore grade is too low to enrich, demanding some special methods to extract the zinc economically $[3,4]$.

The zinc oxide ore could be dissociated using acidic leaching processes, however the presence of contaminants such as $\mathrm{Ca}, \mathrm{Fe}, \mathrm{Mg}$, etc., along with zinc, render the further processing as very complex [5-7]. The recent efforts in literature indicate utilization of an alkali such as ammonia for leaching metals like cobalt, nickel and copper due to the formation of stable metal amine complexes, leading to higher solubility in most cases. Other harmful impurities, such as $\mathrm{Fe}, \mathrm{Pb}, \mathrm{Ca}$, and $\mathrm{Mg}$ precipitate as hydroxides due to their poor complexability with ammonia [8]. However, reports on the process of optimization of the ammonia leaching process for the separation of zinc ores are not available, necessitating such an effort in the field of hydrometallurgy.

The microwave heating is a method of pre-treatment of raw ore commonly utilized in hydrometallurgy [9]. Microwave-assisted leaching in metallurgy and extraction of minerals has been a subject of interest in the last few decades, but most of the microwave-assisted extraction works 
were related by leaching with mineral acids [10]. In the last few years, ultrasonic processes emerged as a preferred alternative for enhancing the leaching efficiency of the metal ores [11]. The merit of the ultrasonic cavitation effect, contributing to an improved rate of leaching is well documented [12-14]. Nevertheless, its application in the hydrometallurgical industry is in its infancy, in particular with respect to ammonia media.

This work attempts to develop a new hydrometallurgical technology to enrich low grade zinc ore in a medium of ammonia and ammonium citrate solutions, utilizing ultrasound and microwave heating [15]. In this connection, the optimal process conditions were identified covering the process parameters of ammonia-ammonium ratio, roasting temperature, ultrasound power, and leaching duration.

\section{Materials and Methods}

\subsection{Materials}

The complicated zinc ore received from Yunnan province of China, was crushed and ground to a powder of size less than $75 \mu \mathrm{m}$, and its chemical composition is recorded in Table 1. The X-ray diffraction (XRD, Rigaku, Japan) pattern of the zinc residue shows the mineralogical content of the sample before and after roasting at various temperatures is shown in Figure 1. It can be seen that XRD analysis shows the smithsonite $\left(\mathrm{ZnCO}_{3}\right)$, hemimorphite $\left(\mathrm{Zn}_{4} \mathrm{Si}_{2} \mathrm{O}_{7}(\mathrm{OH})_{2} \cdot \mathrm{H}_{2} \mathrm{O}\right)$, and gangue, such as calcite $\left(\mathrm{CaCO}_{3}\right)$ and quartz $\left(\mathrm{SiO}_{2}\right)$. All the chemical reagents used in this study were of analytical grade.

Table 1. Chemical composition of the zinc oxide ores (wt \%).

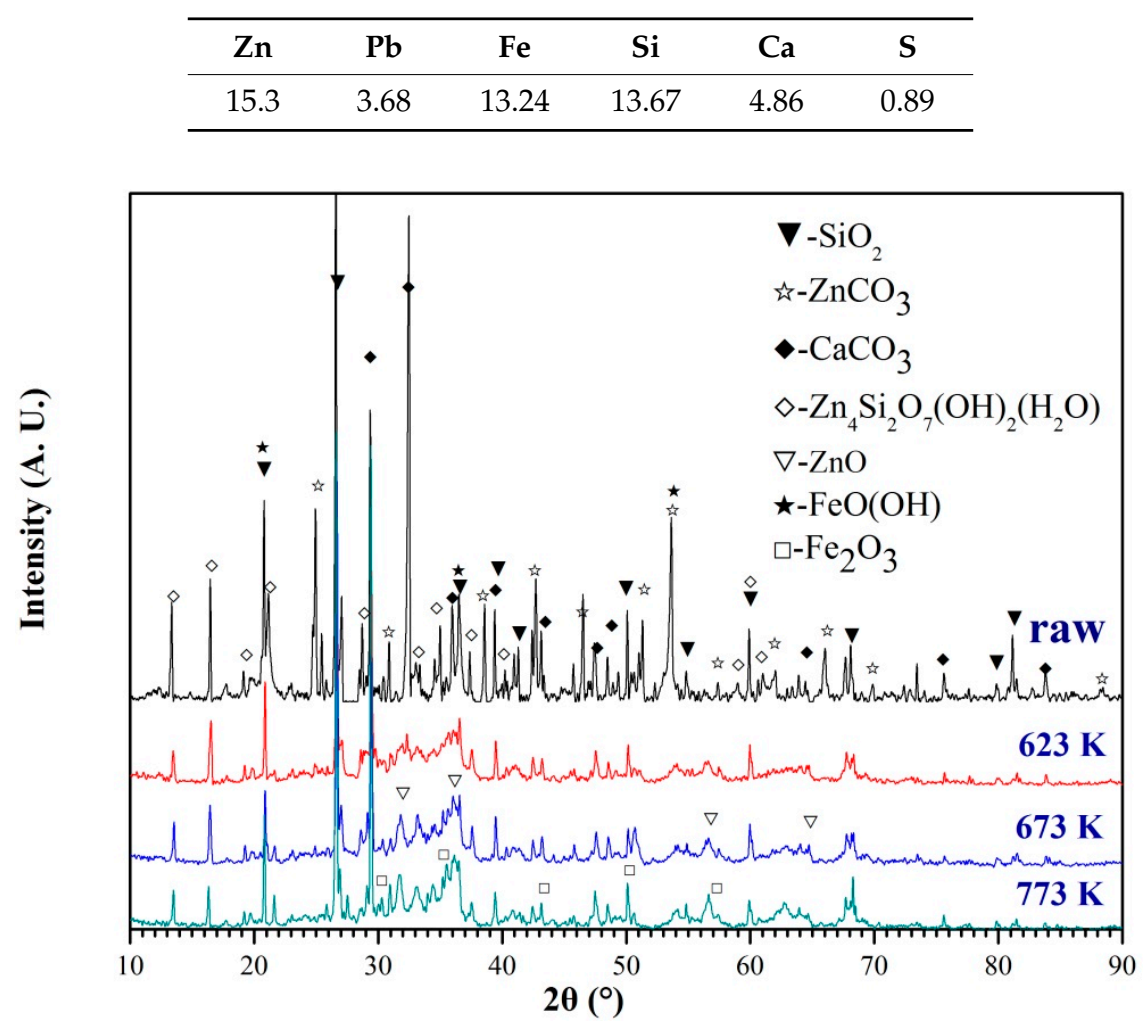

Figure 1. X-ray diffraction (XRD) patterns of complicated zinc ore before and after roasting at various temperatures with microwave power. 


\subsection{Sample Preparation}

The samples were placed in a crucible (Cheng Chen Industrial Co., Ltd., Shanghai, China), evenly spread as a thin layer and exposed to temperatures of 573,623,673, 723, and $773 \mathrm{~K}$, roasted in the atmosphere for a duration of $30 \mathrm{~min}$ in a microwave oven (Maike Wei Microwave Innovation Technology Co., Ltd, Qingdao, China). The duration of $30 \mathrm{~min}$ refers to the time the samples were retained in the furnace after reaching the set temperature. The roasted samples were leached adopting the details provided in the section below.

\subsection{Leaching Experiments}

The microwave roasted sample of $24 \mathrm{~g}$ was taken along with $120 \mathrm{~mL}$ of ammonia of a $5 \mathrm{~mol} / \mathrm{L}$ concentration along with ammonium citrate of a $1.2 \mathrm{~mol} / \mathrm{L}$ concentration into a reaction vessel (Shu bo Industrial Co., Ltd., Sichuan, China) at a default ultrasound power (200-1000 W), default temperature $(298 \mathrm{~K})$ for a default duration of (10-180 $\mathrm{min})$, at a stirring speed of $300 \mathrm{rpm}$ and at a liquid to solid ratio of 5:1. Upon completion of the experiment, the lixivium and leached residue were separated, and the concentration of zinc in the leached solutions was measured. The \% leaching of zinc was calculated in different periods of the experiment. Moreover, the $\mathrm{Zn}$ recovery was estimated by using the equation:

$$
\eta_{\mathrm{Zn}}=\frac{C_{\mathrm{Zn}} \times V}{m \times W_{\mathrm{Zn}}} \times 100 \%
$$

where, $C_{\mathrm{Zn}}, V, m$, and $W_{\mathrm{Zn}}$ represent the $\mathrm{Zn}$ concentration of lixivium $(\mathrm{g} / \mathrm{L})$, the volume of lixivium $(\mathrm{L})$, the mass of the zinc oxide ore (g), and the proportion of zinc in the ore (\%), respectively. The $C_{\mathrm{Zn}}$ was determined by the ICP (ICP-OES, LEEMAN prodigy 7, Hudson, NH, USA).

The effect of ultrasound power on the \% leaching of zinc is assessed by varying the ultrasound power from 200 to $1000 \mathrm{~W}$.

\subsection{Reaction Mechanism}

The citrate and ammonium can be coordinated with zinc to leach the zinc in the mineral to increase the \% leaching of the zinc. The coordination of zinc ions with ammonium is detailed in the reactions below (1) to (4):

$$
\begin{gathered}
\mathrm{Zn}^{2+}{ }_{(\mathrm{aq})}+\mathrm{NH}_{3} \cdot \mathrm{H}_{2} \mathrm{O}_{(\mathrm{aq})}=\left[\mathrm{Zn}\left(\mathrm{NH}_{3}\right)\right]^{2+}{ }_{(\mathrm{aq})}+\mathrm{H}_{2} \mathrm{O} \\
\mathrm{Zn}^{2+}{ }_{(\mathrm{aq})}+2 \mathrm{NH}_{3} \cdot \mathrm{H}_{2} \mathrm{O}_{(\mathrm{aq})}=\left[\mathrm{Zn}\left(\mathrm{NH}_{3}\right)_{2}\right]^{2+}{ }_{(\mathrm{aq})}+2 \mathrm{H}_{2} \mathrm{O} \\
\mathrm{Zn}^{2+}{ }_{(\mathrm{aq})}+3 \mathrm{NH}_{3} \cdot \mathrm{H}_{2} \mathrm{O}_{(\mathrm{aq})}=\left[\mathrm{Zn}\left(\mathrm{NH}_{3}\right)_{3}\right]^{2+}{ }_{(\mathrm{aq})}+3 \mathrm{H}_{2} \mathrm{O} \\
\mathrm{Zn}^{2+}{ }_{(\mathrm{aq})}+4 \mathrm{NH}_{3} \cdot \mathrm{H}_{2} \mathrm{O}_{(\mathrm{aq})}=\left[\mathrm{Zn}\left(\mathrm{NH}_{3}\right)_{4}\right]^{2+}{ }_{(\mathrm{aq})}+4 \mathrm{H}_{2} \mathrm{O}
\end{gathered}
$$

In the process of ammonia leaching, zinc oxide and zinc carbonate dissolve due to the formation of $\mathrm{Zn}(\Pi)$-ammonia complex ion. Thermodynamic calculation [16] shows that in liquid ammonia, all of the $\mathrm{ZnCO}_{3}$ cannot be converted into the solution, but $\mathrm{ZnO}$ can do it easily. Under the condition of the microwave, roasting the $\mathrm{ZnCO}_{3}$ gets converted to $\mathrm{ZnO}$ facilitating leaching with ammonia.

$$
\begin{gathered}
\mathrm{ZnCO}_{3}+4 \mathrm{NH}_{3} \cdot \mathrm{H}_{2} \mathrm{O}_{(\mathrm{aq})}=\mathrm{Zn}\left(\mathrm{NH}_{3}\right)_{4}{ }^{2+}+\mathrm{CO}_{3}{ }^{2-}{ }_{(\mathrm{aq})}+4 \mathrm{H}_{2} \mathrm{O} \\
\mathrm{ZnO}+4 \mathrm{NH}_{3}+\mathrm{H}_{2} \mathrm{O}=\mathrm{Zn}\left(\mathrm{NH}_{3}\right)_{4}{ }^{2+}+2 \mathrm{OH}^{-}{ }_{(\mathrm{aq})} \\
\mathrm{ZnCO}_{3}=\mathrm{ZnO}+\mathrm{CO}_{2}
\end{gathered}
$$




\section{Results and Discussion}

\subsection{Effect of Microwave Roasting on \% Leaching of Zinc}

Figure 2 shows the zinc leaching for the unroasted zinc ore increases with the increase of ammonia concentration, with maximum \% leaching being 59.5\%. Under the same conditions the \% leaching with the microwave roasted ore increased from $64.5 \%$ to $75.2 \%$ (Figure 3). A comparison of the XRD pattern of the raw ore and the residue after leaching are shown in Figure 4. It is conspicuous, that the presence of $\mathrm{ZnCO}_{3}$ is the reason for the low leaching \%. Similarly a comparison of the XRD pattern for the raw ore with the microwave roasted leached residue is shown in Figure 5. The XRD pattern confirms the transformation of $\mathrm{ZnCO}_{3}$ to $\mathrm{ZnO}$ after microwave roasting, which contributes to the increased \% leaching of $\mathrm{Zn}$.

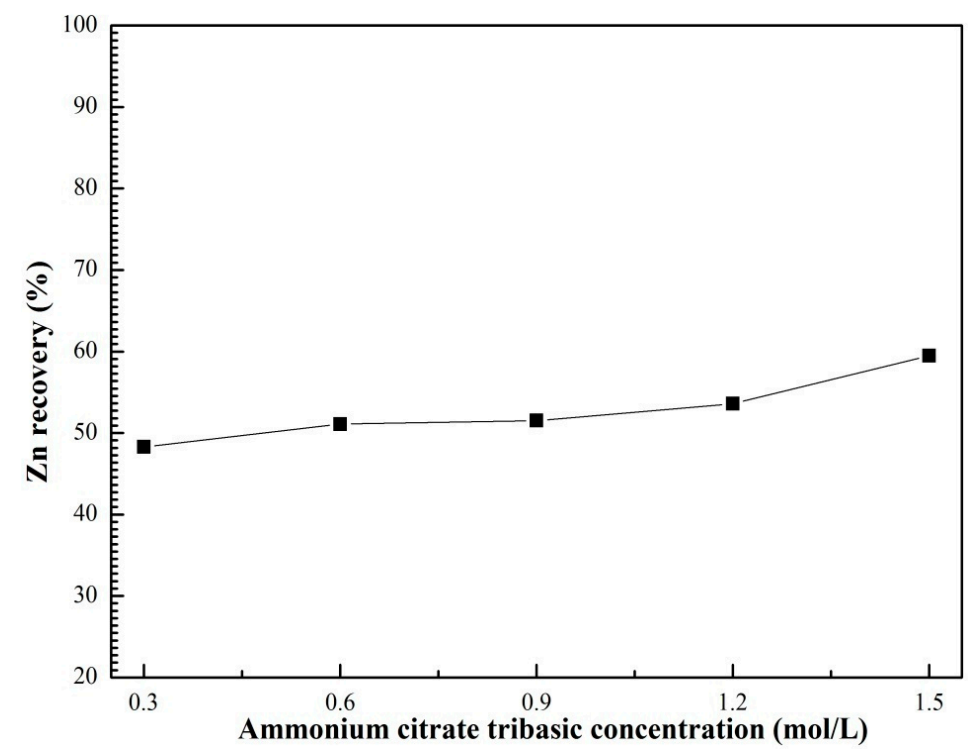

Figure 2. Effects of different ammonium citrate concentrations (from 0.3 to $1.5 \mathrm{~mol} / \mathrm{L}$ ) on leaching efficiency of zinc from the unroasted ores.

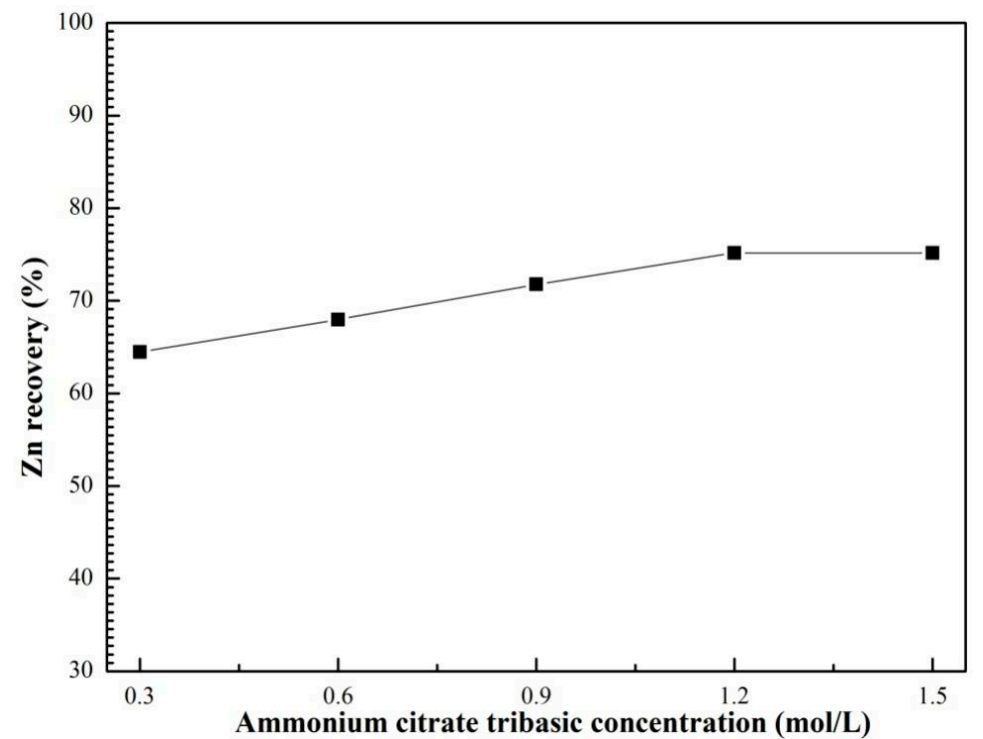

Figure 3. Effect of $5 \mathrm{~mol} / \mathrm{L}$ ammonia with different ammonium citrate concentrations (from 0.3 to $1.5 \mathrm{~mol} / \mathrm{L}$ ) on the zinc recovery of the roasted ores at $673 \mathrm{~K}$. 


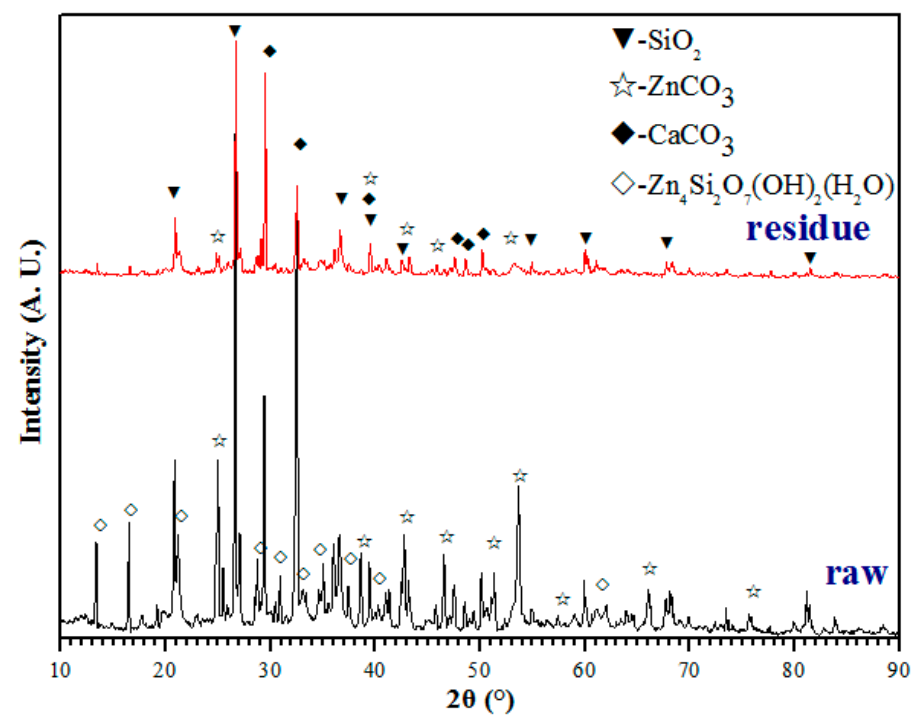

Figure 4. XRD patterns of the complicated zinc ores before raw ore and the residue after the raw ore leached at the same condition.

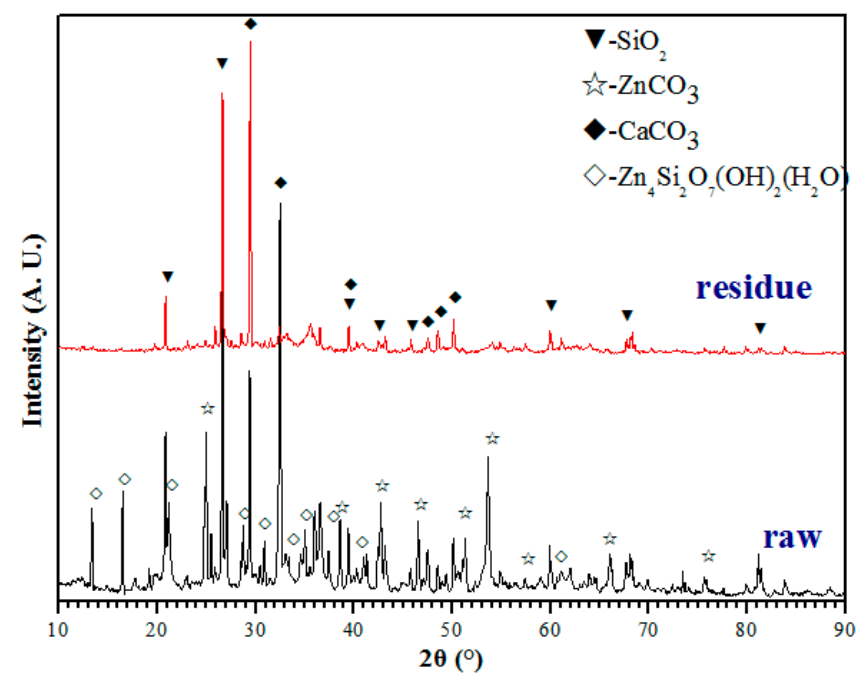

Figure 5. XRD patterns of the complicated zinc ores before and after roasting at $673 \mathrm{~K}$.

\subsection{Effect of Microwave Roasting Temperature}

The effect of the roasting temperature on the \% leaching of zinc is shown in Figure 6. The \% leaching was found to increase with an increase in the microwave roasting temperature until $673 \mathrm{~K}$, with a marginal decrease beyond $673 \mathrm{~K}$. The highest \% leaching is as high as $71.77 \%$. Under the same conditions, the unroasted ore yielded only $51.5 \%$. In Figure 1, the $\mathrm{ZnCO}_{3}$ phase in the mineral disappears and the $\mathrm{ZnO}$ phase appears in $673 \mathrm{~K}$, which improves the highest yield at $673 \mathrm{~K}$. At temperatures higher than $673 \mathrm{~K}$, the decrease in zinc yield could be attributed to the formation of zinc ferrite, which has poor capacity to be assimilated by ammonia. Therefore, when the calcination temperature of the mineral exceeds $673 \mathrm{~K}$, the \% leaching of the calcined ore decreased. Zhang et al. [17] also have reported that zinc oxide ore calcined at $673 \mathrm{~K}$, and alkali leaching resulted in the highest recovery, while at temperatures higher than $673 \mathrm{~K}$, the tendency of the calcined ore to form zinc ferrite, contributed to a lower $\mathrm{Zn}$ recovery. 


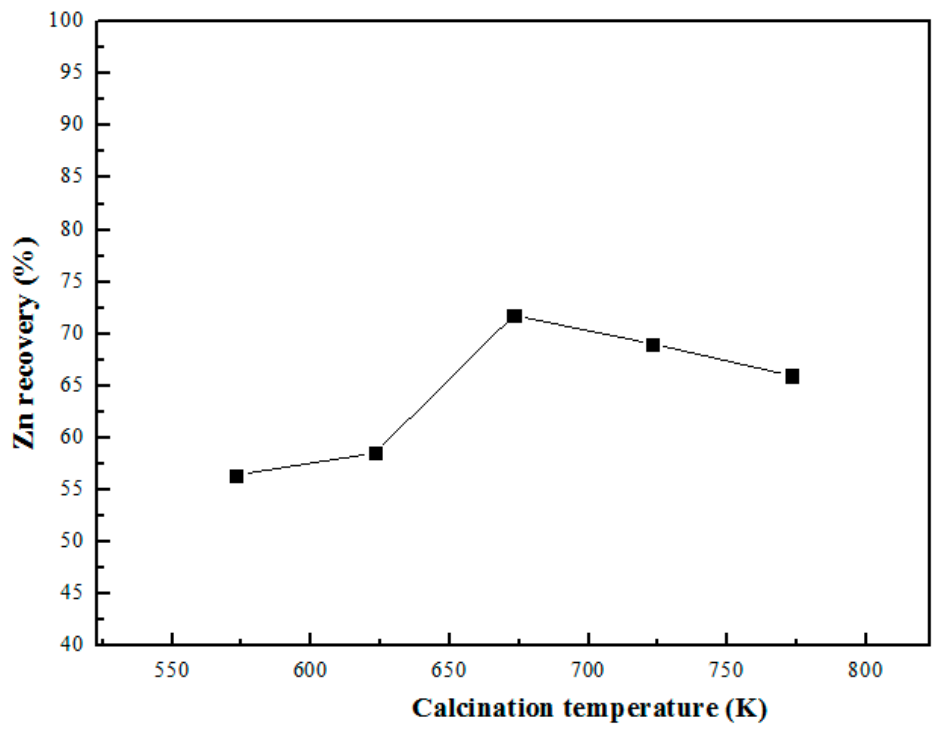

Figure 6. Zinc leaching recovery after roasting at different calcination temperatures.

\subsection{Effects of Ultrasound Power}

Figure 7 shows the effect of the ultrasonic power on the $\% \mathrm{Zn}$ recovery covering an ultrasonic power range of 200 to $1000 \mathrm{~W}$. The figure shows the maximum recovery is observed at an ultrasonic power of $600 \mathrm{~W}$, while beyond that it was found to decrease. The increase in the \% $\mathrm{Zn}$ recovery with an increase in the ultrasonic power can be attributed to the increase in the cavitation effect, the mechanical stirring effect, which increased the degree of turbulence in the solid-liquid interface that contributed to a higher recovery. In addition, the micro-jet generated by the cavitation of the ultrasonic wave will promote the diffusion of the leachant to the surface of the mineral, liberating the zinc ions. At ultrasonic powers in excess of $600 \mathrm{~W}$, a marginal decrease in the $\mathrm{Zn}$ recovery could be attributed to the ultrasonic power contributing to the volatilization of ammonia and the decomposition of ammonium chloride in the leaching system. The reduction of ammonium ions in the leaching solution inevitably contributed to a reduction in the $\mathrm{Zn}$ recovery. This phenomenon is also reported by Li et al. [18].

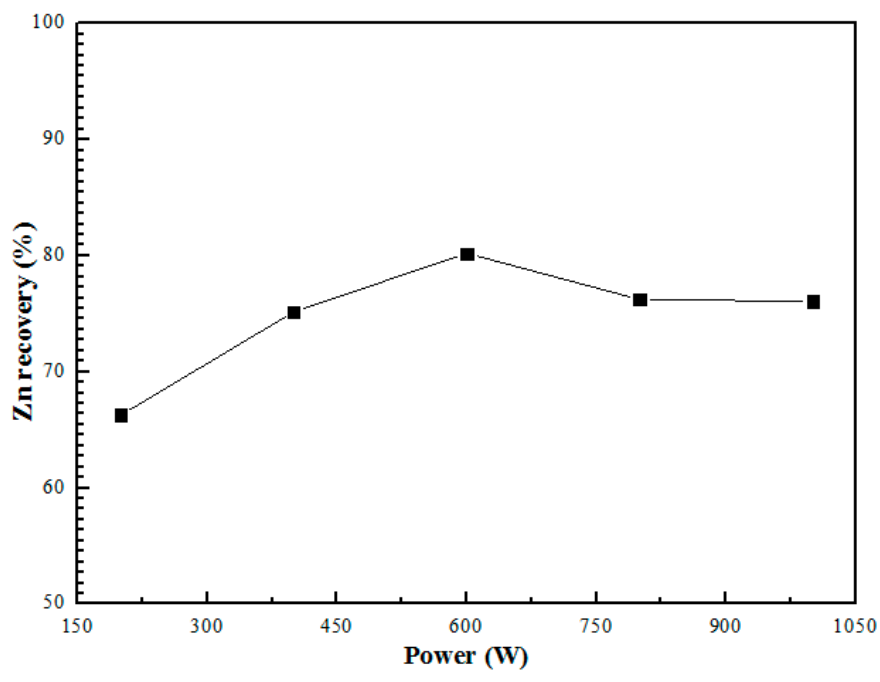

Figure 7. Effects of ultrasonic power on zinc recovery. 
For the zinc ore microwave roasted at $673 \mathrm{~K}$, and leaching conditions at a temperature of $298 \mathrm{~K}$, a solid to liquid ratio of 1:5, stirring speed of $300 \mathrm{rpm}$, reaction time of $60 \mathrm{~min}$, ammonia concentration of $5 \mathrm{~mol} / \mathrm{L}$ and with an ammonium citrate concentration of $1.2 \mathrm{~mol} / \mathrm{L}$, the maximum \% $\mathrm{Zn}$ recovery obtained was $80.2 \%$.

\subsection{Effect of Leaching Time with Ultrasound}

The influence of the leaching duration on the $\mathrm{Zn}$ recovery is presented in Figure 8. With increases to the leaching duration, an increase in the $\mathrm{Zn}$ recovery was observed, the maximum $\mathrm{Zn}$ leaching was $88.57 \%$ for a duration of $120 \mathrm{~min}$.

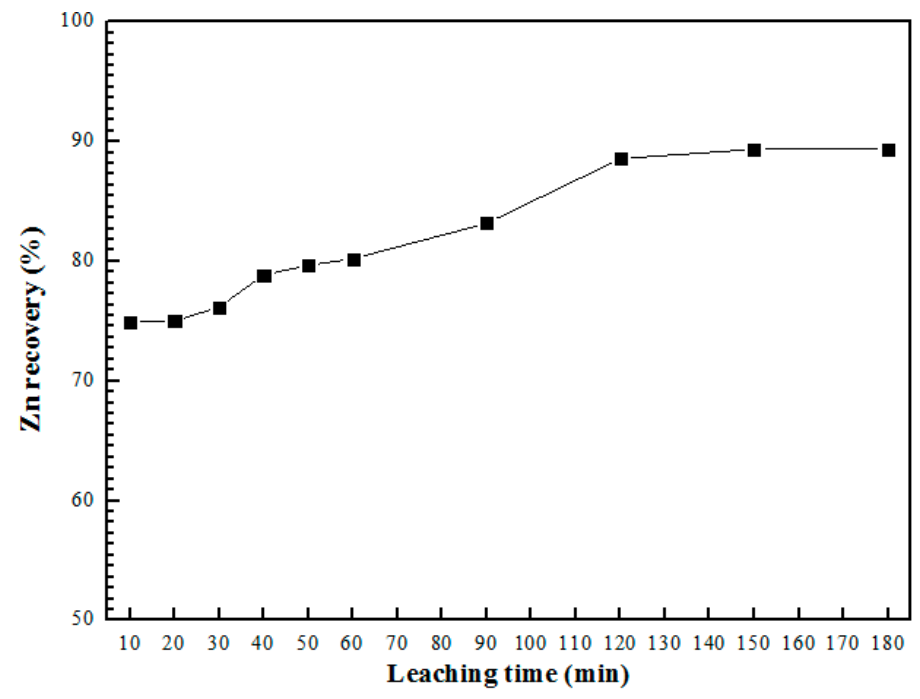

Figure 8. Effects of leaching time on the Zn recovery.

\subsection{Characterization Analysis}

The leached zinc oxide ores with the maximum $\mathrm{Zn}$ recovery were dried at $373 \mathrm{~K}$ and ground for Chemical composition detection, and the major elements were listed in Table 2. It can be seen that the leached zinc oxide ore mainly consisted of $\mathrm{Zn}, \mathrm{Pb}, \mathrm{Fe}, \mathrm{Si}, \mathrm{Ca}$, and $\mathrm{S}$ elements. It is generally known that the most $\mathrm{Pb}, \mathrm{Fe}, \mathrm{Si}$, and $\mathrm{Ca}$ containing compounds can't be dissolved in the ammonia and ammonium citrate solutions. With the reduction of zinc in the ores, the contents of the elements such as $\mathrm{Pb}, \mathrm{Fe}, \mathrm{Si}$, and $\mathrm{Ca}$ significantly increase. For example, the ratio of lead and zinc in the ore before roasting was 1 to 4.18, and that in the leaching residue was as high as 1 to 0.52 . During roasting, the oxidation of $S$ element can occur, so the content of $S$ in the leached ores decreases.

Table 2. Chemical composition of leached zinc oxide ores (wt \%).

\begin{tabular}{cccccc}
\hline $\mathbf{Z n}$ & $\mathbf{P b}$ & $\mathbf{F e}$ & $\mathbf{S i}$ & $\mathbf{C a}$ & $\mathbf{S}$ \\
\hline 2.73 & 5.23 & 18.22 & 20.1 & 7.31 & 0.31 \\
\hline
\end{tabular}

\section{Conclusions}

The zinc recovery from complicated zinc ores could be accomplished successfully with the maximum recovery being $88.57 \%$ under the experimental conditions, of a roasting temperature of $673 \mathrm{~K}$, leaching temperature of $298 \mathrm{~K}$, stirring speed of $300 \mathrm{rpm}$, total ammonia concentration of $5 \mathrm{~mol} / \mathrm{L}$ with an ammonium citrate concentration of $1.2 \mathrm{~mol} / \mathrm{L}$, liquid to solid ratio of $5: 1$, ultrasound power of $600 \mathrm{~W}$ and a leaching time of $120 \mathrm{~min}$.

Acknowledgments: This work was supported by National Natural Science Foundation of China (51604135). 
Author Contributions: Haoyu Li, Shiwei Li, Libo Zhang, Jinhui Peng conceived and designed the experiments; Haoyu Li, performed the experiments and analyzed the data; Libo Zhang, Jinhui Peng contributed reagents/materials/analysis tools; Shaohua Yin, Chandrasekar Srinivasakannan modified the paper before submission; all the authors analyzed the data and wrote the paper.

Conflicts of Interest: The authors declare no conflict of interest.

\section{References}

1. Chen, A.; Zhao, Z.W.; Jia, X.; Long, S.; Huo, G.S.; Chen, X.Y. Alkaline leaching Zn and its concomitant metals from refractory hemimorphite zinc oxide ore. Hydrometallurgy 2009, 97, 228-232. [CrossRef]

2. Ferdous, R.; Khan, F.; Veitch, B.; Amyotte, P.R. Methodology for computer-aided fault tree analysis. Process Saf. Environ. Prot. 2007, 85, 70-80. [CrossRef]

3. Yang, T.; Rao, S.; Zhang, D.; Wen, J.; Liu, W.; Chen, L. Leaching of low grade zinc oxide ores in nitrilotriacetic acid solutions. Hydrometallurgy 2016, 161, 107-111. [CrossRef]

4. Moradi, S.; Monhemius, A.J. Mixed sulfide-oxide lead and zinc ores: Problems and solutions. Miner. Eng. 2011, 24, 1062-1076. [CrossRef]

5. Anjum, F.; Shahid, M.; Akcil, A. Biohydrometallurgy techniques of low grade ores: A review on black shale. Hydrometallurgy 2012, 117-118, 1-12. [CrossRef]

6. Huisman, J.L.; Schouten, G.; Schultz, C. Biologically produced sulphide for purification of process streams, effluent treatment and recovery of metals in the metal and mining industry. Hydrometallurgy 2006, 83, 106-113. [CrossRef]

7. Crundwell, F.K. The mechanism of dissolution of minerals in acidic and alkaline solutions: Part III. Application to oxide, hydroxide and sulphide minerals. Hydrometallurgy 2014, 149, 265-275. [CrossRef]

8. Ding, Z.; Yin, Z.; Hu, H.; Chen, Q. Dissolution kinetics of zinc silicate (hemimorphite) in ammoniacal solution. Hydrometallurgy 2010, 104, 201-206. [CrossRef]

9. Lovás, M.; Murová, I.; Mockovciaková, A.; Rowson, N.; Jakabský, Š. Intensification of magnetic separation and leaching of Cu-ores by microwave radiation. Sep. Purif. Technol. 2003, 31, 291-299. [CrossRef]

10. Pinto, I.S.S.; Soares, H.M.V.M. Microwave-assisted selective leaching of nickel from spent hydrodesulphurization catalyst: A comparative study between sulfuric and organic acids. Hydrometallurgy 2013, 140, 20-27. [CrossRef]

11. Wang, X.; Srinivasakannan, C.; Duan, X.H.; Peng, J.H.; Yang, D.J.; Ju, S.H. Leaching kinetics of zinc residues augmented with ultrasound. Sep. Purif. Technol. 2013, 115, 66-72.

12. Choi, J.K.; Jayaprakash, A.; Chahine, G.L. Scaling of cavitation erosion progression with cavitation intensity and cavitation source. Wear 2012, 278, 53-61. [CrossRef]

13. Lei, Y.; Chang, H.; Guo, X.; Li, T.; Xiao, L. Ultrasonic cavitation erosion of 316L steel weld joint in liquid $\mathrm{Pb}-\mathrm{Bi}$ eutectic alloy at $550{ }^{\circ} \mathrm{C}$. Ultrason. Sonochem. 2017, 39, 77-86. [CrossRef]

14. Lebon, G.S.B.; Tzanakis, I.; Djambazov, G.; Pericleous, K.; Eskin, D.G. Numerical modelling of ultrasonic waves in a bubbly Newtonian liquid using a high-order acoustic cavitation model. Ultrason. Sonochem. 2017, 37, 660-668. [CrossRef] [PubMed]

15. Fischmann, A.J.; Dixon, D.G. Awaruite $\left(\mathrm{Ni}_{3} \mathrm{Fe}\right)$ as a nickel resource-leaching with ammoniacal-ammonium solution containing citrate and thiosulfate. Hydrometallurgy 2009, 99, 214-224. [CrossRef]

16. Zhang, Y. The High Temperature Aqueous Solution Thermodynamics Data Calculation Handbook; Metallurgical Industry Press: Beijing, China, 1983.

17. Zhang, Y.; Deng, J.; Chen, J.; Yu, R.; Xing, X. Leaching of zinc from calcined smithsonite using sodium hydroxide. Hydrometallurgy 2013, 131-132, 89-92. [CrossRef]

18. Li, J.G.; Zhao, R.S.; Liu, H.C. Recovery of metal values from spent lithium-ion batteries. Acta Scientiarum Nat. Univ. Sunyatseni 2007, 46, 256-257.

(C) 2017 by the authors. Licensee MDPI, Basel, Switzerland. This article is an open access article distributed under the terms and conditions of the Creative Commons Attribution (CC BY) license (http://creativecommons.org/licenses/by/4.0/). 